\title{
0 portador de transtorno esquizofrênico na atenção básica: caminhos e descaminhos na busca do cuidado
}

\section{The Schizophrenic patient in primary health care: paths and mistakes searching for help}

\author{
Gilson Holanda Almeida ${ }^{1}$ \\ 1. Docente do Centro Universitário Christus - Unichristus, PhD.
}

\section{Resumo}

Introdução: Há três décadas, iniciou-se a implementação de políticas visando à desconstrução de um modelo de atenção em saúde mental centrado no hospital e que permitisse gradativamente à Atenção Básica romper a dicotomia entre ações de saúde coletiva e atenção individual. Permanece campo de interesse avaliar o trabalho das equipes da Estratégia da Saúde da Família na Atenção Básica focado nas demandas dos doentes mentais graves e de seus familiares. Objetivos: configurar histórias da doença de portadores de esquizofrenia e seu percurso na busca do atendimento na Atenção Básica. Métodos: Estudo qualitativo realizado, por meio de relato de caso, em três Unidades Básicas de Saúde de Fortaleza-Ceará que haviam passado pelo Matriciamento, com dados coletados em visitas domiciliares com portadores de esquizofrenia utilizando-se entrevistas em profundidade para configurar histórias de vida. Resultados: Os achados refletem a desorganização e a incomunicabilidade de instâncias prestadoras de serviços de saúde, a demora na identificação dos casos emergentes, a falta de agenda nos atendimentos, ausência de individualização do sujeito e necessidade de maior preparo dos profissionais para o desafio de tratar portadores de esquizofrenia na Atenção Básica. Conclusão: As práticas de Saúde Mental, numa perspectiva mais compreensiva, ainda estão à espera de uma inserção mais nítida e operante dentro da Atenção Básica.

Palavras-chave: Atenção Básica. Esquizofrenia. Entrevista Psiquiátrica Padronizada. Unidade Básica de Saúde.

\begin{abstract}
Introduction: Three decades ago, there began the implementation of policies aiming at the deconstruction of a model in mental health care centered in the hospital so as to allow the Primary Health Care gradually break the dichotomy between public health actions and individual attention. However, it remains important to evaluate how the teams of the Family Health Strategy have been working in primary care demands of patients with severe mental illness. Objectives: To configure the history of illness of schizophrenic patients and the route taken in the pursuit of meeting their demands in Primary Care. Methods: A qualitative study carried out in three Basic Health Units in Fortaleza-Ceará that had passed through the matricial process, with data collected in home visits with schizophrenic patients using in-depth interviews to set up life stories. Results: The findings reflect the disorganization and the lack of communication instances that should provide health, expose the delay in identifying the emerging cases, the lack of agenda, lack of individualization of the subject and the needs for better preparation of professionals in the challenge of treating patients with schizophrenia in Primary Care. Conclusion: Mental Health practices, in a more comprehensive approach, are still waiting for a clearer and operative inclusion within Primary Health Care.
\end{abstract}

Key-words: Primary Health Care. Schizophrenia. Mental Status Schedule. Primary Health Unit.

\section{INTRODUÇÃO}

A reformulação global das políticas de saúde no Brasil, a exemplo do que vem ocorrendo em outros países que reformaram seus modelos sanitários tendo por base os cuidados primários universais, como o Canadá, a Espanha e, em especial, o Reino Unido, confere hoje particular importância à Saúde Mental na Atenção Básica ${ }^{1}$. Desde a década de setenta a Organização Mundial de Saúde já advogava para esse nível da atenção a ênfase do tratamento². As mudanças propostas visavam à inflexão para um modelo que superasse o hospital como o principal serviço ${ }^{3,4}$. Alguns marcos para essa superação são identificados, entre outros, no advento do Sistema Único de Saúde (SUS) pela
Constituição de 1988; na criação do Programa de Saúde da Família (PSF) em 1994 - hoje Estratégia de Saúde da Família (ESF), concebida como uma das estratégias para a estruturação da rede de Atenção Básica de Saúde visando articular promoção e assistência e fazer a ruptura da dicotomia entre as ações de saúde coletiva e as de atenção individual5,6,7,8,9; no contínuo desenvolvimento do SUS e na implantação de novos programas e políticas, como os Núcleos de Apoio à Saúde da Família que viriam ampliar a abrangência e o escopo das ações da Atenção Básica e sua resolubilidade; no modelo de assistência integral em Saúde Mental criado pelo Lei $N^{\circ}$. 10.216, ao estabelecer

Correspondência: gilsonholanda@gmail.com.br

Conflito de interesse: Declaro não haver conflito de interesses pertinentes. Recebido em 14 Jan 2013; Revisado em 20 Mai 2013; Aceito em 20 Mai 2013 
um sistema de referência e contrarreferência integrado com as unidades, funcionando de forma harmônica, complementando-se, não se opondo nem se sobrepondo normas umas às outras, não concorrendo nem competindo entre $\mathrm{si}^{10}$. Entre um leque de vantagens, propugnava-se que as práticas integrais, unificadas em um só lugar, romperiam a dicotomia entre o físico e o mental, diminuiriam o estigma, permitiriam o acesso fácil para rotinas e crises, seriam capazes de abordar todas as dimensões dos problemas (social, física, ambiental), proveriam informação continuada, comunicação efetiva entre os profissionais e propiciariam a construção de uma fortaleza na relação terapêutica que individualiza o paciente ${ }^{11}$. Contudo, permanece campo de interesse avaliar como as ESFs vêm trabalhando as demandas de pacientes portadores de esquizofrenia e de seus familiares na Atenção Básica, os limites e as possibilidades dessas práticas ${ }^{12}$.

A contribuição dos transtornos mentais, na população em geral, é significativa. Estratégias centradas na família mostram que a doença mental responde por um terço das demandas, geralmente associadas a outros fatores como qualidade de vida, violência doméstica, doenças crônicas e infecciosas não tratadas, etc. É alta a prevalência dos transtornos mentais comuns (TMC), com índice global de doenças mentais de $37,8 \%$ em usuários das EPSFs ${ }^{13}$. Essas taxas seriam provavelmente maiores, caso os profissionais da Atenção Básica recebessem ação educativa nos moldes recomendados pela OMS14, que os tornaria mais sensíveis a reconhecer sintomas indicativos dos problemas de saúde mental ${ }^{15}$. A Atenção Básica emerge, portanto, como locus importante para as práticas de Saúde Mental. Propostas com forte orientação na Atenção Básica geram resultados de saúde melhores e mais equitativos, mais eficientes, têm menores custos e podem alcançar maior satisfação do usuário do que os sistemas de saúde que têm apenas uma orientação frágil na Atenção Básica ${ }^{16}$.

Entre os transtornos mentais, a esquizofrenia se reveste de particular importância, requerendo esforços e desafios no manejo da doença. Paradigma da doença mental grave e a mais comum das psicoses crônicas, a esquizofrenia muitas vezes traz consequências psicológicas e sociais devastadoras tanto para os portadores como para seus familiares ${ }^{17}$. Trata-se de uma doença grave que atinge cerca de $1 \%$ da população, com início geralmente precoce, na adolescência ou na vida adulta jovem, comprometendo os anos de vida mais produtivos. Pelo comprometimento de várias funções psíquicas, acarreta numerosas perdas a seu portador; por sua evolução usualmente crônica, na maioria dos casos exige seguimento e tratamento por toda a vida. Os custos financeiros com o tratamento, diretos e indiretos, são elevados, e fazem dessa condição um grave problema de saúde pública ${ }^{18,19}$, devendo-se conjugar tratamentos medicamentosos com abordagens psicossociais para que os melhores resultados sejam obtidos ${ }^{20}$.

\section{OBJETIVOS}

Configurar a história da doença de pacientes portadores de esquizofrenia e o percurso realizado por eles e seus familiares na Atenção Básica na busca do atendimento das suas demandas.

\section{MATERIAIS E MÉTODOS}

Estudo qualitativo, trabalhando com um universo de significados, motivos, aspirações, crenças, valores e atitudes dos sujeitos envolvidos ${ }^{21,22}$, realizado por meio do relato de casos em três Unidades Básicas de Saúde (UBS) de Fortaleza-Ceará que haviam passado pelo Matriciamento ${ }^{1,23}$ e contavam com o apoio de um NASF24. Os dados foram coletados em visitas domiciliares com portadores de esquizofrenia, valendo-se de um roteiro semiestruturado com pontos de ancoragem no DSM IV-TR que permitiram a configuração de histórias de vida por meio de entrevistas em profundidade ${ }^{25}$ que configuraram histórias de vida com enfoque na doença e no percurso dos pacientes e das famílias na busca de atenção à saúde. Para se chegar aos entrevistados, contou-se com informação de Agentes Comunitários de Saúde (ACS) visto que estes detêm maior conhecimento sobre o território, fato associado à ausência de registros nas UBS que permitissem identificação dos sujeitos desejados. Foram realizadas oito entrevistas, cinco delas descartadas por terem os pacientes diagnósticos diferentes de esquizofrenia. Mesmo não se confirmando a hipótese de esquizofrenia, em um dos casos optou-se por mantê-lo, por se tratar de transtorno mental grave com rica problemática e equívocos na condução. Pacientes/ familiares assinaram o TCLE, conforme Resolução no 196/96 do CNS26. O projeto foi submetido e aprovado pelos CEP da Faculdade de Saúde Pública da USP e da Escola de Saúde Pública do Ceará; nesta última, foi protocolado sob o $\mathrm{N}^{\circ}$. 119/2008, de 2 de abril de 2008.

\section{RELATOS DOS CASOS}

\section{Caso I}

Após identificação por ACS de jovem portadora de doença mental, dirigimo-nos à sua casa, onde fomos recebidos pelos pais - ele cozinheiro, e ela encarregada dos afazeres domésticos. A paciente tem 15 anos; é solteira, não estuda nem trabalha. De aparência descuidada e frágil, mantém-se cabisbaixa, não se comunica adequadamente, ri muito - riso pueril, desconfiado. Olha para a mãe como a se reabastecer de confiança. Os pais relatam que a doença se manifestou há dois anos, quando, sem causa aparente, a filha passou a se comportar de maneira agressiva, destruindo os objetos do lar, chorando, falando que queria um namorado e casar, falas repetidas à exaustão. É a penúltima de uma série de cinco filhos, entre 26 e 12 anos, dos quais apenas uma, casada, não reside com o grupo. Sem comemorativos de doença quando criança, fora, todavia, muito calma 
e isolada, sem interação com outras crianças, à exceção dos irmãos. Frequentava escola, que cedo abandonou, pois afirmava que ninguém gostava dela e chamavam-na de doida e feia [sic]. Não aprendeu a ler nem a escrever. A doença surgiu ao tempo em que a irmã mais velha saiu de casa; a mãe vê correlação entre esses fatos. Não participa dos afazeres domésticos. Não gosta de seu corpo e evita se olhar no espelho. Inveja a irmã mais nova por ter boa aparência. Os passatempos estão restritos a ouvir música, ver TV e jogos eletrônicos. Na fantasia, dialoga com artistas da televisão. Recusa fazer refeições junto com a família, não se alimenta a contento nem respeita horas das refeições. Habitualmente, dorme tarde da noite. A família entende tratar-se de um caso de doença mental e se culpa por não ter buscado auxílio médico antes: são evangélicos e confiaram apenas na Providência divina [sic]. O ACS agendou atendimento em um CAPS-infantil para depois de dois meses, posteriormente cancelado e reagendado para mais três meses. Exceto a visita ao ACS, não existe orientação de qualquer outro profissional de saúde.

A examinada dá pouca colaboração com a entrevista, não estabelece contato visual, responde às indagações com riso pueril e respostas curtas ou evasivas. Usa argumentos do tipo "é porque é" ou "não sei". Hoje, não mais é agressiva ou destrutiva, como no passado. Está desorientada no tempo e no espaço, desatenta, sem relato ou indícios de alterações do senso-percepção, aparência descuidada, déficit de memória. O pensamento é regredido, desorganizado e concreto. $\mathrm{O}$ afeto é inapropriado, sem modulação adequada para diferentes situações. Funcionamento intelectual rebaixado. Apesar de a família reconhecer a necessidade de tratamento, conviç̧ões religiosas interferiram, retardando a busca do cuidado que se esperaria.

\section{Comentários}

O quadro é compatível com esquizofrenia desorganizada ou hebefrênica (295.10, DSM-IV-TR27) instalada há cerca de dois anos em personalidade pré-mórbida marcada pela ausência de interações sociais e com preferência pela vida solitária. Apesar de morarem a uma quadra de um CSF, o único contato com o sistema de saúde se fez por meio do ACS, pessoa que goza de simpatia junto à família. Crenças religiosas retardaram a busca do cuidado. Quando se faz o agendamento para serviço de atenção em saúde mental, esse é postergado em pelo menos cinco meses. Os familiares são tolerantes em conviver com a enfermidade, imobilizados, com aceitação tácita da situação sem indignação ou revolta. Falha o serviço em não acenar com presteza à demanda existente. Falha a família em abdicar das prerrogativas cidadãs dos seus direitos à saúde e deveres do Estado. Como consequência, perde-se a oportunidade do diagnóstico e de intervenções precoces, com potenciais prejuízos na evolução e no prognóstico.

\section{Caso II}

Dona Luísa tem 71 anos, é separada do marido, aposentada, tem baixa escolaridade. Abandonada pelo marido há mais de 30 anos, criou sozinha os sete filhos. Sua casa é bastante pobre e se situa próximo a uma UBS. Três dos filhos residem no entorno da casa. Dedicava-se a um centro espírita anexo à sua morada, onde recebia clientes e fazia "trabalhos". A família depende dela fortemente e mostra estrutura bastante caótica. Um dos filhos com quem reside é homicida, já cumpriu pena na prisão, bebe diariamente e está sendo investigado por suspeita de ter abusado da própria filha, menor de idade sob a guarda da avó. Uma filha é dependente de substâncias psicoativas e com frequência furta pertences de casa para comprá-las. Há, ainda, um terceiro filho, que mora em casa separada e parece ter estrutura familiar melhor constituída. Antes de adoecer, a entrevistada cuidava de todos os afazeres domésticos e assumia financeiramente a maior parte das despesas. A doença começou há dois meses. Antes lúcida, comunicativa, sociável, sempre à frente dos problemas da família, de repente deixou de reconhecer as pessoas, não mais chamava os filhos nem os netos pelos nomes. Não dormia à noite. A família desconhece o evento que possa ser tomado como desencadeante. Ao exame, mostrou-se com aparência limpa, vestimentas adequadas, é amistosa, embora sem colaboração efetiva, está desatenta e com o discurso totalmente desconexo, desorganizado, não conseguindo responder nenhuma pergunta de modo coerente. Segundo familiares, fala sozinha, como se ouvisse e visse pessoas irreais, talvez espíritos [sic]. Há crises de choro e episódios de agressividade verbal dirigida aos familiares. Apesar das alterações, continuou fazendo a comida da casa e cuidando dos demais afazeres. A família recorreu ao Centro de Saúde próximo à casa, no qual Dona Luísa vinha se tratando de hipertensão e hiperglicemia. Seu médico não tinha vaga na agenda e nem podia ir até sua casa; daí restar à família apenas aguardar. Talvez seja doença de Alzheimer ou "encosto", conjecturavam. Há cerca de duas semanas, foi levada por um amigo para atendimento em hospital psiquiátrico terciário nas imediações de casa. Familiares desconhecem os procedimentos/orientações realizados, apenas registram que foram fornecidos medicamentos, todavia não utilizados- um dos remédios desapareceu e o outro estava intacto, não sendo dado por medo de que pudesse agravar mais ainda o quadro. De concreto, para enfrentamento do caso, apenas o compromisso do ACS de continuar tentando o contato com o médico de família para agendar uma visita.

\section{Comentários}

O caso expõe fragilidades e desencontros no trato com a saúde. Apesar da gravidade da situação, em quase dois meses não havia um diagnóstico, encaminhamento ou tratamento adequado. A construção da referência na Atenção Básica parece ser um ponto positivo - tratam o ACS 
com cordialidade, esperam o atendimento do médico que já acompanhava a paciente. No entanto, há superlotação nas agendas e insuficiência de técnicos para viabilizar a atenção. A paciente foi atendida em hospital terciário sem o esgotamento de instâncias mais plausíveis e sem que a família tivesse pleno conhecimento desse atendimento. A Atenção Terciária não referenciou para outro nível de atenção nem agendou retorno. Um dos medicamentos desapareceu, o outro não foi administrado. O ACS é impotente para ajudar. As causas da doença continuam não trabalhadas ou discutidas. Finalmente, em uma família de estrutura tão caótica, com problemas de drogas, possível abuso de menor pelo próprio pai, homicídio e etilismo, impunha-se um diagnóstico da saúde mental do grupo provocando intervenções. A Lei da Reforma da Saúde Mental prevê situações como essa, nos seus dispositivos, passíveis de serem trabalhadas pelas equipes do Matriciamento. $O$ diagnóstico de esquizofrenia foi aventado. Falam a favor da hipótese o discurso e o comportamento desorganizados e a disfunção sócio-ocupacional. Contra, o aparecimento tardio em personalidade, ao que parece, sem antecedentes mórbidos, ausência de pródromos, curto tempo da doença, ausência de sintomas negativos, ideação persecutória. Alucinações auditivas ou visuais não estão suficientemente caracterizadas. Todavia, trata-se de uma situação psicótica bastante grave, reclamando intervenção imediata. 0 quadro abrupto fala contra doença demencial do tipo Alzheimer, hipótese que é levantada pelos familiares. Não se descarta, contudo, outra patologia orgânica, como um processo expansivo ou vascular. Mesmo na impossibilidade de confirmação diagnóstica para esquizofrenia, o relato foi mantido, pela riqueza dos mecanismos e situações evidenciados associados a um manejo crítico.

\section{Caso III}

Duas jovens portadoras de transtorno mental residem com a mãe em casa alugada próxima a uma UBS e atualmente estão sob os cuidados de uma equipe do NASF. Na entrevista domiciliar a que se procedeu, a mãe informou que suas filhas, de 23 e 21 anos, têm problemas mentais graves desde o nascimento. Uma terceira filha, saudável, é casada e mora com o marido. Oriundas de cidade do interior, foram abandonadas pelo pai alcoolista há 20 anos. Contam com pensão alimentícia, aposentadoria por invalidez de uma das filhas e o auxílio do programa bolsa-família. Tiveram boa assistência pré-natal e no parto, mas já no primeiro ano de vida, ambas as filhas, apresentaram convulsões afebris, de frequência semanal. Receberam cuidados de um neuropediatra e prescrição de medicamentos. As convulsões diminuíram, nunca desapareceram. $\mathrm{Na}$ idade escolar, frequentaram escola, onde não ficaram: a mais nova não aprendia e a mais velha se afastava do contato com os colegas, achava que implicavam com ela. Abandonaram a escola. Em casa, viviam trancadas quais prisioneiras. Mais tarde, aos 10 e 12 anos, passaram a frequentar um Centro de Atenção Psicossocial (CAPS), onde receberam atenção de qualidade; contudo não desenvolveram habilidades. Continuavam apresentando crises convulsivas. Ao cabo de algum tempo, foram desligadas do serviço para gerar vagas para pessoas mais comprometidas. Continuaram o tratamento em um serviço de atenção infanto-juvenil de um hospital psiquiátrico terciário da Capital. O tratamento proposto foi o medicamentoso - anticonvulsivantes para os ataques e neurolépticos para as alterações da conduta e do comportamento. Aos 15 anos, a filha do meio se casou. A mãe passou a viver com um companheiro de mais de 70 anos de idade, a princípio um pai para todas [sic], mas que posteriormente molestou a filha mais velha. Após a separação do companheiro, a família se mudou para a Capital. As moças brigavam muito entre si e não se relacionavam com estranhos. A mais velha era mais calada, a mais nova irritada e agressiva. Com a maioridade da mais velha, ambas passaram a ser atendidas em um CAPS geral, absorvidas em um tratamento que não as diferenciava nem estimulava, simplesmente eram prescritos os mesmos medicamentos. Mais recentemente, estão sendo atendidas por uma UBS, com a ajuda de um ACS que agendou a participação dos técnicos do NASF. À entrevista, as jovens mostram comportamentos diferentes: a mais nova é mais efusiva; a mais velha é retraída. São obesas, com vários dentes ausentes ou mal conservados, trajam roupas simples e apropriadas. Exploro seus pensamentos, sentimentos, afetividade, socialização. A mais nova mostra acentuada pobreza conceitual. Apesar de efusiva, não se comunica adequadamente, exibe um riso pueril, expressões afetivas bizarras (agarra, beija, abraça), dá pararrespostas, o pensamento situa-se em um nível concreto e há relato de explosões de raiva com agressividade. A mais velha denota melhor capacidade intelectual, com discurso mais elaborado, porém desorganizado. Percebe suas limitações e sofre com isso. Na fantasia, imagina que se relaciona com os personagens da TV. A mãe é evangélica e quando vai aos cultos deixa as filhas trancadas, exceto quando vizinhos e fiéis da igreja solidariamente ficam com as moças enquanto ela se ausenta. A mãe faz avaliação positiva dos serviços de saúde que utilizaram e do interesse dos profissionais com quem conviveu. Realça o empenho do ACS, a quem se refere como "um anjo das nossas vidas" que ajuda na renovação das receitas, agenda as consultas e leva-as ao médico. Também elogia o trabalho dos técnicos do NASF, que têm se deslocado até sua casa.

\section{Comentários}

A demanda por cuidados de saúde parece em certa medida ter sido atendida. Na tenra idade, foram cuidadas e medicadas por especialistas. Na escola, foram admitidas sem segregação, embora não esteja claro que tipo de estimulação receberam. Mais tarde, o CAPS do interior presta um relevante serviço, acolhendo-as, oferecendo transporte, atenção multiprofissional e medicamentos. Com o desligamento, em face de melhoras, foram atendidas em um serviço infanto-juvenil de hospital- 
escola terciário. Há indícios de que aí tenha havido possível limitação no atendimento, centrado no psiquiatra e tendo o medicamento como único recurso. Tampouco foi aventada a possibilidade de dar tratamento diferenciado às duas, absorvidas em uma única identidade. Ao atingir a maioridade, a mais velha é transferida para outro serviço - um CAPS-adulto. Para facilitar a vida da mãe, a irmã mais nova a acompanha. As mesmas características do antigo CAPS se repetem: tratamento focado no médico e no medicamento, e as pacientes unificadas em uma mesma abordagem. $\mathrm{O}$ trabalho do ACS, pela importância e reconhecimento, mais uma vez ganha o relevo mostrado nos relatos anteriores. É ele quem faz a intermediação entre pacientes-instituições (CAPS, UBS), agenda consultas, visitas do NASF, busca medicamentos. O NASF mostra atendimento de clínica ampliada, identificando diferentes demandas, com agendamento clínico, de odontologia, de nutricionista, acenando para a introdução de terapêuticas ressocializantes, quebrando o modelo de atenção centrado exclusivamente no médico. Também merece registro a construção de uma rede solidária que venha a englobar vizinhos e Instituições Religiosas.

As jovens são portadoras de epilepsia associada a retardo mental. A mais nova tem funcionamento mais comprometido, compatível com o grau de idiotia. A mais velha tem um retardo moderado, com melhor capacidade de abstração, associado a um quadro psicótico compatível com esquizofrenia indiferenciada (295.90 do DSM-IV-TR), expresso na incoerência do discurso, desorganização do comportamento, afeto embotado e rígido, dificuldade de formar e manter vínculos, de se individuar, traços paranoides de funcionamento (as pessoas generalizadamente não gostam dela). Talvez agora, com o trabalho efetivo do ACS e a interferência do NASF, tenha oportunidade de receber uma atenção individualizada que explore possíveis potenciais e rompa com a díade que formou com a irmã.

\section{CONSIDERAÇÕES FINAIS E CONCLUSÕES}

A reformulação global das políticas de saúde e a influência dos princípios da reforma psiquiátrica conferem hoje grande importância à Saúde Mental na Atenço Básica. A presença do doente mental em sua residência é uma realidade, quer pelos critérios que dificultam internações, quer pela existência de serviços extra-hospitalares. Essa perspectiva, nascida do convívio alargado do paciente portador de transtorno mental com a sua família, reforça a importância da Atenção Básica no tratamento. Apesar desse lócus privilegiado, ainda se convive com um sistema em que tais práticas não mostram uma inserção nítida e operante. Alguns aspectos mostrados nos relatos de caso, ao reconstituírem o itinerário de pacientes e familiares na demanda por cuidados de saúde mental, ressaltam a desorganização e a incomunicabilidade de instâncias prestadoras de saúde. O modelo assistencial em Saúde Mental no Brasil tem um arcabouço teórico e um sistema legal bem construído, à espera tão somente de que as diferentes partes que o compõem exercitem suas competências de maneira solidária e dialogante a um só tempo. A confrontação entre o desenho do modelo teórico proposto e sua operacionalização, possivelmente mostra que essas propostas nem sempre estão apontadas na mesma direção.

Os relatos partilham aspectos comuns: remetem a pacientes portadores de transtornos mentais graves; a Atenção Básica falha ao perder a oportunidade de construir a singularidade dos sujeitos, de praticar a clínica ampliada e fazer o apoio familiar que os três casos requerem; apesar da gravidade dos casos, o agendamento é precário, postergado; não obstante o empenho de alguns técnicos da ESF, as situações poderiam ter sido melhor trabalhadas; e o reconhecimento da importância do papel do ACS.

Os resultados do estudo permitem sugerir a necessidade de maior preparo dos profissionais para dar conta do desafio de tratar portadores de esquizofrenia na Atenção Básica; é importante que se enfatize a necessidade de desenvolvimento de um trabalho conjunto que envolva gestores, terapeutas, familiares e pacientes e que mantenha uma melhor observância das competências dos diferentes níveis de atenção, buscando um funcionamento harmônico e integrado entre elas. $\mathrm{O}$ estudo pode ser secundado por outros em diferentes realidades e práticas regionais da Saúde Mental na Atenção Básica e, desse modo, preencher lacunas do conhecimento.

\section{REFERÊNCIAS}

1. Tófolli LF, Fortes S. Apoio Matricial de Saúde Mental na Atenção Primária no município de Sobral, CE: o relato de uma experiência. SANARE [Internet]. 2005/2007 [acesso 2012 Nov 25];6(2):15-23. Disponível em: http://sanare.emnuvens.com.br/sanare/article/view/151/143.

2. World Health Organization $(\mathrm{CH})$. Primary health care-report of the international conference on PHC: Alma-Ata, USSR. Geneva: WHO; Set 1978:6-12.

3. Bezerra Júnior B, Amarante P. A Psiquiatria sem hospício: contribuições ao estudo da reforma psiquiátrica. In: Rotelli F, Amarante P. Reformas psiquiátricas na Itália e no Brasil: aspectos históricos e metodológicos. Rio de Janeiro: Relume-Dumará; 1992.
4. Jorge MAS, Alencar PSS, Belmonte P, Reis VLM. Políticas e práticas de saúde mental no Brasil. In: Escola Politécnica de Saúde Joaquim Venâncio, organizador. Textos de apoio políticas de saúde. Rio de Janeiro: Editora Fiocruz; 2005: 207-222.

5. Buss PM. Promoção da saúde e qualidade de vida. Ciênc Saúde Coletiva, 2000;5(1):163-177.

6. Buss PM. Uma introdução ao conceito de promoção da saúde. In: Czeresnia D. Promoção da saúde: conceitos, reflexões, tendência. Rio de Janeiro: Fiocruz; 2003.

7. Mendes EV. Um agente para a saúde. São Paulo: Hucitec; 1996. 
8. Goya AN. Promoção da saúde, poder local e saúde da família: estratégias para a construção de espaços locais saudáveis, democráticos e cidadãos humanamente solidários e felizes. SANARE 2003;4(1):51-56.

9. Souza DS. O desenvolvimento da estratégia da saúde da família no Rio Grande do Sul. Bol Saúde. 2003;17:10-13.

10. Almeida GH. Os caminhos da integralidade da atenção: uma proposta de organização dos níveis de atenção em saúde mental. In: Anais do 23 Congresso Brasileiro de Psiquiatria; 2005; Belo Horizonte, 2005.

11. Lester H, Glabasby J, Tylee A. Integrated primary mental health care: threat or opportunity in the new NHS? Br J Gen Pract. 2004; 54(501): 285-291.

12. Almeida GH. Possibilities and concerns regarding acceptance and treatment of schizophrenics under Primary Health Care as seen by managers, therapists, relatives and patients [tese de doutorado]. São Paulo: Faculdade de Saúde Pública da USP; 2010.

13. Mari JJ, Jorge MR, Kohn R. Epidemiologia dos transtornos psiquiátricos em adultos. In: Mello MF; Mello AF.; KOHN, R, organizadores. Epidemiologia da saúde mental no Brasil. Porto Alegre: Artmed; 2007. p. 129-141.

14. World Health Organization - WHO (CH). Division of Mental Health. A users guide to the Self-Reporting Questionnaire (SRQ-20). Geneva: WHO; 1994

15. Bandeira M, Freitas LC, Carvalho Filho JGT. Avaliação da ocorrência de transtornos mentais comuns em usuários do Programa de Saúde da Família. J Bras Psiquiatr. 2007;56(1):41-47.

16. Pan American Health Organization (US). Renovação da APS nas Américas - Documento de posicionamento da OPAS/OMS. Washington (DC): PAHO; 2005.
17. Roder V. O programa terapêutico e seus cinco subprogramas. In: Terapia integrada da esquizofrenia. São Paulo: Lemos; 2001. Capítulo 2, p. 49-84.

18. Louzã Neto MR, Elkis H. Esquizofrenia: abordagem atual. São Paulo: Lemos; 1999.

19. Louzã Neto MR, Shirakawa I. O enfoque médico atual. In: Louzã Neto MR, Shirakawa I, Barros L. Esquizofrenia: dois enfoques complementares. São Paulo: Lemos; 1999. p. 13-27.

20. Assis JC, Villares CC, Bressan RA. Entre a razão e a ilusão - desmistificando a loucura. São Paulo: Segmento Farma Editores; 2008.

21. Minayo MCS, organizadora. Pesquisa social: teoria, método e criatividade. 24. ed. Petrópolis: Vozes; 1994.

22. Minayo MSC. O desafio do conhecimento: pesquisa qualitativa em saúde. 9. ed. rev. aum. São Paulo: Hucitec; 2006.

23. Figueiredo MD, Onocko-Campos R. Saúde Mental na atenção básica à saúde de Campinas, SP: uma rede ou um emaranhado? Ciênc Saúde Coletiva. 2009;14(1);129-138.

24. Brasil. Ministério da Saúde. Portaria GM no 154, de 24 de janeiro de 2008. Cria os Núcleos de Apoio à Saúde da Família - NASF. Brasília; 2008.

25. Biasoli-Alves ZM, Dias da Silva, MHGF. Análise qualitativa de dados de entrevista: uma proposta. Paidéia (Ribeirão Preto). 1992. 2:61-69.

26. Brasil. Conselho Nacional de Saúde. Resolução 196/96. Decreto n. 93.933 de janeiro de 1987. Estabelece critérios sobre pesquisa envolvendo seres humanos. Bioética; 2006:4(2 supl):15-25.

27. American Psychiatric Association (US). DSM-IV-TR Diagnostic and statistical manual of mental disorders. 4th ed. Washington (DC): APA; 2000.

Como citar este artigo / How to cite this article:

Almeida GH. 0 portador de transtorno esquizofrênico na atenção básica: caminhos e descaminhos na busca do cuidado. J Health Biol Sci. 2013 Abr-Jun; 1(2):84-89. 